\title{
Gastrointestinal Stent Update
}

\author{
Sung-Gwon Kang \\ Department of Interventional Radiology, Seoul National University Bundang Hospital, Seongnam, Korea
}

The use of self-expanding metallic stents in the upper gastrointestinal tract, placed under radiologic imaging or endoscopic guidance, is the current treatment of choice for the palliation of malignant gastrointestinal outlet obstructions. Advances in metallic stent design and delivery systems have progressed to the stage where this treatment is now considered a minimally invasive therapy. Metallic stent placement will broaden further into the field of nonsurgical therapy for the gastrointestinal tract. To date, metallic stents placed in the esophagus, gastric outlet, colorectum, and bile ducts are not intended to be curative, but rather to provide a palliative treatment for obstructions. The evolution of metallic stent technology will render such procedures not only palliative but also therapeutic, by enabling local drug delivery, and the use of biodegradable materials will reduce procedure-related complications. (Gut Liver 2010;4(Suppl. 1):S19-24)

Key Words: Gastrointestinal tract; Interventional procedures; Metallic stents

\section{INTRODUCTION}

The use of metallic stent in gastrointestinal tract is one of the most influencing evolutions in the history of both therapeutic endoscopy and interventional radiology. The first experimental and clinical application of metallic stent in non-vascular organ was tracheobronchial tree by Wallace and his colleagues. ${ }^{1}$ They used Gianturco stent in their study. In 1990, Fujiwara et al. ${ }^{2}$ reported experimental use of metallic stents in the trachea, esophagus, and urethra of five dogs. Karnel et al. ${ }^{3}$ reported their experience with metal stent in malignant stenosis in a colon interposition in 1991, Kozarek et al. ${ }^{4}$ placed Z stents in patients with previous surgical bypass of the stomach in 1992. Neuhaus et al..$^{5}$ firstly reported endoscopically placed expandable metallic stent for malignant dysphagia, and Song et al. ${ }^{6}$ reported fluoroscopically inserted metallic stent for benign and malignant esophageal lesions. Since these innovative reports metallic stent technology was evolving rapidly during these two decades. In this review article, we describe history, and most recent technology of self-expandable metallic stent for treatment of gastrointestinal tract disease.

\section{HISTORY OF SELF-EXPANDABLE METALLIC STENT IN GASTROINTESTINAL TRACT}

The first self-expandable metallic stent is Gianturco Z-stent (Wilson-Cook, Winston-Salem, NC, USA). The Gianturco Z-stent is still available in uncovered and covered version. Covered Z-stent has flared design at both ends to provide stability and minimize migration. Modified silicone-covered Gianturco expandable metallic stents were placed in eight patients with esophageal cancer by Song et al. in 1991. In clinical setting covered gastrointestinal stent has a critical disadvantage such as migration after successful stent placement. To prevent migration of covered stent, Song et al. ${ }^{6}$ reported new design of modified Gianturco stent with shoulder at both ends. The Strecker stent was second self-expandable metallic stent for esophageal obstruction. Grundy ${ }^{7}$ reported their initial clinical result with Stecker stent (currently Ultraflex; Microinvasive, Natick, MA, USA) which is knitted metallic stent with highly flexibility. Most currently available esophageal stent can be retrievable from Song et al. ${ }^{8}$ s report in 1997. In this report, they put drawstring

Correspondence to: Sung-Gwon Kang

Department of Interventional Radiology, Seoul National University Bundang Hospital, 300 Gumi-dong, Bundang-gu, Seongnam 463-707, Korea

Tel: +82-31-787-7603, Fax: +82-31-787-4011, E-mail: gangsg@snu.ac.kr

DOI: $10.5009 /$ gnl.2010.4.S1.S19 
at the proximal inner margin of the stent. The use of Nitinol wire is another milestone in the history of gastrointestinal stents. By using Nitinol wire currently variable metallic stent design such as braided, or knitted stent can be developed.

\section{STAINLESS STEEL STENT}

The Gianturco Z-stent (Cook, Bloomington, IN, USA) is currently available in both covered and uncovered design. In covered design polyethylene membrane is used. It has an inner diameter of $16 \mathrm{~mm}$ in its mid portion with flared both ends up to $25 \mathrm{~mm}$ in outer diameter. Gianturco Z-stent can be delivered with 28-F outer diameter tube. Elgiloy is a biomedical grade cobalt-chromium-iron-nickel-molybdenum alloy which is used for Wallstent (Boston Scientific, Natick, MA, USA). The Wallstent is a self-expanding stent made from a biomedical stainless-steel alloy with a radiopaque core, filaments woven in a tubular fashion, and flexible construction. The Wallstent is mounted on a 6-Fr (RP Delivery System) or 7-Fr (Unistep Plus Delivery System) carrying catheter. The Unistep Plus Delivery System is made of coaxial tubes which allow recapture as indicated by the limit marker and has radiopaque marker bands which aid in accurate placement of the stent. The endoprosthesis is available in a diameter of 10 or $12 \mathrm{~mm}$ and length of 6-9 $\mathrm{cm}$. The stent diameter selected should be approximately 1-2 mm larger than the diameter desired. Deployed lengths reflect expansion to the desired diameter. Constricting the stent to a smaller diameter will cause a longer deployed length, depending on the degree of foreshortening ratio. On average, a $0.5-\mathrm{mm}$ change in diameter yields a $10-15 \%$ change in length. Once the desired diameter is reached, no additional reduction in stent length should occur. The Wallstent is a bare stent with an area that is not in contact with the biliary wall. The metal free surface area (the area not in contact with the biliary wall) was provided by the manufacturer for all stent diameters. The results found that the stent free area was approximately $80 \%$ fully open to nearly $50 \%$ constrained. In addition, the Wallstent endoprosthesis is magnetic resonance compatible, with the only disadvantage of some image artifacts. ${ }^{9}$

\section{NITINOL BILIARY STENT}

Nitinol is a Nickel Titanium alloy which has a shape memory, and super-elastic characteristic. Since first report for biliary Nitinol stent in 1991, currently available most biliary stents are made of Nitinol. Castano et al. ${ }^{10}$ re- ported comparative study between surgical palliation and metallic stent in malignant biliary obstruction. This study enrolled 86 patients (mean age, 66 years; range, 43-78 years) including 40 patients in group 1 (surgery group) and 46 patients in group 2 (stent group). Technical success was $95 \%$ in group 1 and $93 \%$ in group 2. Functional biliary decompression was obtained $88 \%$ in surgical group and $91 \%$ in stented group. Stent group had lower rates for procedure-related mortality ( 2 vs $7.5 \%$; $\mathrm{p}=0.01$ ), a lower frequency of early complications (8.7 vs 45\%; $\mathrm{p}=0.02$ ), and a shorter hospital stay (median, 6 vs 12 days; $\mathrm{p}=0.01$ ). Recurrent jaundice occurred for three patients in surgery group (7.5\%) and eight patients in group $2(17.3 \%) \quad(p=0.198)$. Despite the early benefits of stenting, no significant difference in the median overall survival between the two groups was found (group 1, 163 days; group 2, 178 days; $\mathrm{p}=0.11$ ). Currently many different designs of biliary metallic stent are available; laser etched stent or wire braided stent, bare metal stent or covered stent, stent with sharp edge or blunt edge, and different physical properties such as radial force, foreshortening, flexibility, corrosion resistance, chronic durability, conformability, and the size of delivery system. Zilver $^{\circledR} 635$ (Cook), SMART (Johnson \& Johnson, Cordis, Miami Lake, FL, USA), SelfX (Jostent; Abbott Laboratories, Abbott Park, IL, USA) stent (10 $\mathrm{mm}$ in diameter) (Cook) which is a laser-cut Nitinol stent mounted in an extra slim 6-Fr to 7-Fr delivery catheter. ${ }^{11}$ Niti-S (Taewoong, Seoul, Korea), Bonastent (Standard Sci-tech, Seoul, Korea), Hanarostent (MI-Tech, Seoul, Korea), EGIS (S\&G Biotech Inc., Seoul, Korea), and Ultraflex (Boston Scientific, Natick, MA, USA) are wire braided biliary stent mounted in 7-Fr to 8-Fr delivery system. The Viabil (Gore, Newark, DE, USA) is a self-expanding covered stent made of an ePTFE/FEP tubular lining externally supported by a helical Nitinol stent with radiopaque markers at both ends. The inner lining is made of low-porosity, ultrathin, 0.010-mm-thick, ePTFE/FEP. Two versions are available on the market, one with transmural drainage side holes which are present in the lining for 2 $\mathrm{cm}$ along the proximal end, and a fully covered one. The purpose of these holes is to avoid obstruction of the intrahepatic side ducts or the cystic duct. If an endoprosthesis with transmural drainage holes is selected, the middle and hepatic end radiopaque rings demarcate the boundaries of the holed region. The endoprosthesis is available in a diameter of 8 or $10 \mathrm{~mm}$ and a length of 4 , 6,8 or $10 \mathrm{~cm}$ in both the holed and the fully covered version. According to the manufacturer the Viabil should extend at least $2 \mathrm{~cm}$ proximal and distal to the margins of the stricture. Due to the Nitinol lining, total expansion 
is reached approximately 24 hours after placement but the endoprosthesis length is not subject to variation. Positioning should not result in excessive length into the duodenum. There are not enough data at this moment regarding Viabil magnetic resonance compatibility. Finally, Viabil stents can be retrieved either percutaneously or endoscopically even several months after placement. ${ }^{9}$ Covered Wallstent (Boston Scientific) and ComVi (Taewoong) are also covered biliary stent but there are bare metal portion at both ends. ${ }^{12}$ EGIS double covered stent (S\&G Biotech Inc.) is also covered stent and it has a very good conformability because membrane and stent struts are not fixed. Regarding primary patency and ingrowth rate, ePTFE/FEP-covered stents have shown to be significantly superior to bare Nitinol stents for the palliation of malignant jaundice caused by inoperable pancreatic head cancer and pose comparable cost and complications. Use of a covered stent does not significantly influence overall survival rate; nevertheless, the covered endoprosthesis seems to offer result in fewer reinterventions and better quality of patient life. ${ }^{13}$

Complete biliary drainage using metallic stent in hilar cholangiocarcinoma is very challenging but helpful procedure for the patients who are suffered from jaundice, cholangitic sepsis, or pruritus. Classic method of metallic stent placement is "Y" configuration; one stent from right, another stent from left PTBD tract or from endoscopic route. Lee et al. ${ }^{14}$ reported new design of biliary metallic stent for hilar cholangiocarcinoma. In this report, the transverse stent with the $\mathrm{Y}$ configuration, called a $\mathrm{Y}$ stent (Niti-S Biliary Y stent; Taewoong), was used a hybrid of spiral and $Z$ stents. The mesh of the central part of the $\mathrm{Y}$ stent becomes bigger by removing the $\mathrm{Z}$ component, and making wide open mesh. Another usual metallic stent can be placed through this wide open mesh. In addition to this classic technique, " $\mathrm{T}$ " and " $\mathrm{X}$ " configuration stent placement has been reported. " $\mathrm{T}$ " configuration can be used in hilar cholangiocarcinoma with Bismuth type 2, and " $\mathrm{X}$ " configuration in Bismuth type 3a.

\section{NITINOL ESOPHAGEAL STENT}

Esophageal metallic stent placement is a well-accepted and effective treatment option for dysphagia. The main limitations of this procedure are the recurrent dysphagia due to tumor and nontumor tissue growth, stent migration, and food impaction. Now a day a covered stent is the mainly used stent type for the palliation or malignant dysphagia. This stent covering prevents tumor tissue from growing into the mesh of the stent, which may occur in more than $25 \%$ of the patients treated with an uncovered stent, but those covered stents are associated with a higher migration rate than bare metal stent even though they have some special design for migration such as flare, or shoulder. ${ }^{15}$ Increasingly, fully covered self-expanding plastic stents (SEPS) and now fully covered metal stents have been used to treat a variety of benign esophageal conditions as well as cancer. Several stent designs are available in the United States and many more internationally. ${ }^{16}$ Partially Silicone covered Wallflex with a $18.5 \mathrm{~F}$ delivery system has a multiple wire braided construction which allows the stent to adjust to forces from the esophageal anatomy such as peristalsis and strictures. Niti-S esophageal stent has a unique design which is uncovered second layer over silicone covered first layer to prevent migration. Evolution stent (Cook Medical, Limerick, Ireland) is designed to overcome the problem of recurrent dysphagia. The stent has an internal and external silicone membrane to resist tumor and granulation tissue, on the one hand, and to facilitate food passage through the stent, on the other. To prevent migration, the Evolution stent has uncoated flanges on both ends resulting in a "dogbone" shape and allowing the stent to embed itself in the esophageal wall. In addition, the stepwise release system and the possibility to recapture when the stent is up to halfway deployed enables precise positioning of the stent. ${ }^{15}$ Conio et al. ${ }^{17}$ evaluated the safety and efficacy of a SEPS to manage relapsing dysphagia in patients previously treated with a partially covered self-expanding metal stent (SEMS). In 13 patients previously treated with a SEMS for malignant dysphagia, the SEPS was successfully placed in a single treatment session for all patients. The resolution of dysphagia persisted until patient death (from tumor progression). The mean survival after the SEPS insertion was 4 months (range, 3-8 months). This case series supports the use of a SEPS to palliate dysphagia from tissue in/overgrowth of a SEMS. Commercially available esophageal stents that have been used in the stomach or colon include the Gianturco Z-stent (Wilson-Cook), Wallstent (Boston Scientific), Ultraflex Nitinol mesh stent (Microinvasive), and Esophacoil (IntraTherapeutics, Eden Prairie, MN, USA). Unique antimigration designs are used in many different esophageal stents. SX-ELLA (Ella-CS, Hradec Kralove, Czech Republic) has a flip-flop type of antimigration ring design which is circumferentially attached to the proximal stent. $^{18}$

\section{NITINOL PYLORIC STENT}

In 1997, Uno et al., ${ }^{19}$ Januschowski $^{20}$ reported stent 
placement in the patients with gastric outlet stenosis. Malignant obstruction of the gastric outlet is an critical event that causes nausea, vomiting, dysphagia, and then nutritional/electrolyte deterioration in a patient's quality of life. Although surgical bypass is an available option in these patients, but the morbidity and mortality is relatively high. Peroral covered expandable Nitinol stent has been placed in 19 patients successfully. In this report, they discussed double layered stent placement; bare metal stent and covered stent inside of it to prevent migration and tumor ingrowth. ${ }^{21} \mathrm{Kim}$ et al. $^{22}$ placed bare metal stent in 49 patients, and among them $28.5 \%$ showed early restenosis due to tumor ingrowth. Tumor ingrowth was more frequently occurred in post-operative anastomotic recurrence. They also recommend the placement of covered stent or simultaneous dual stents to prevent early restenosis especially for the patient with anastomosis site obstruction. Various types of covered gastroduodenal stents are currently available. A polyurethane-covered Niti-S stent is woven from Nitinol mono filament in an interlacing pattern. Both ends of the stent are flared to prevent migration. Note the string at the proximal (oral side) end of the stents for removal of the stent endoscopically. A Hanaro stent is woven from a single Nitinol wire in an interlocking pattern and covered with silicon membrane. The stent has a bare part at the proximal end to prevent migration. A Dual duodenal stent (S\&G Biotech Inc.) is composed of a bare stent and a partially covered stent that is designed to be placed coaxially. The inner bare stent is knitted from a single Nitinol wire, and both its ends are flared. The outer, partially covered stent has three parts: a proximal bare Nitinol stent, nylon mesh, and a distal bare stent. In addition to these stents, Wallflexduo, Ultraflex, are also used for gastric outlet obstruction.

\section{NITINOL COLORECTAL STENT}

Colonic obstruction is an emergency condition which should be treated immediately. Colorectal stents are being used for palliation and as a "bridge to surgery" in obstructing colorectal carcinoma. Tejero et al. ${ }^{23}$ described new procedure for the treatment of colorectal neoplastic occlusion which involves the following three phases: first, placing a metallic stent at the point of the stenosis of the colon, which enables the acute obstruction phase to be solved; second, recovering the general state of the patient, make an definite treatment plan, and mechanically preparing the colon; third, performing regulated and final surgery. Choo et al. ${ }^{24}$ described flexible covered stent effectively relieved acute colonic obstruction secondary to malignant rectosigmoid neoplasm. Covered stent placement can allow patients to undergo single-stage surgery in most cases and provided palliative decompression in cases of inoperable or disseminated disease. Ultraflex Precision Colonic, Wallstent Enteral (Boston Scientific), Evolution Colonic Stent (Cook), Hanarostent Colorectal (MI-Tech), Niti-S Colorectal (Taewoong), and SX-ELLA (Ella-CS, Hradec Kralove, Czech Republic). Colorectal stent are currently used in the market. Deployed diameter of colorectal stent ranges from $20 \mathrm{~mm}$ to $30 \mathrm{~mm}$, and the delivery system is $10-\mathrm{F}$.

\section{DRUG ELUTING STENT}

The failure of gastrointestinal stents frequently occurred from ingrowth and overgrowth of the device by the tumor cells or benign granulation tissue. The overgrowth and ingrowth may result in restenosis and shortening stent patency and patient's survival. Guo et al. ${ }^{25}$ described 5-FU eluting esophageal stent. The 5-FU concentration in the stent touching segment is higher than other part of esophagus, while the 5-FU concentration in mucosal layer is higher than that in muscle layer. With the increase of drug loading, the drug concentrations in esophageal tissues and serum increase, and cellular desquamation of stent-touching epithelial surface become increasingly severe by SEM. Based on the results; the 5-FU-loaded esophageal stent operates long-term local drug delivery with great efficiency. Paclitaxel is an extremely potent, dose-dependent inhibitory effect on human gallbladder epithelial cells, pancreatic adenocarcinoma cells, and fibroblasts in vitro. Local delivery of paclitaxel using covered metallic biliary stent is now under research in many centers. The purpose of local delivery is to prolong stent patency, and local control of malignancy. Paclitaxel containing biliary stent caused epithelial denudation with moderate mucosal inflammation, mucinous metaplasia, and bile duct thickening and fibrosis. However, no significant complication, such as cholangitis or perforation, was observed in this study. Lee et al. ${ }^{26}$ concluded metallic stent with a paclitaxel-incorporated membrane can be used safely in the normal bile duct. Another study about local delivery in bile duct compared paclitaxel-eluting metallic stents and control stents, mucosal hyperplasia was seen in 3 of 6 dogs in the drug eluting group, but none of the 5 control dogs, after 6 weeks. In this study, authors concluded that drug eluting stents are safe in normal canine biliary tracts and are without technical complications, provide a firm basis for clinical trials of drug eluting covered metallic biliary stents. However, local drug delivery from the drug eluting stent resulted in 
significant histologic changes. Therefore, it is important to choose a drug in adequate concentrations which can exert antitumor effect without damaging the adjacent normal biliary mucosa. ${ }^{27}$ Infection is another arm in complications of metallic biliary stent which is a palliative approach for the treatment of diseases involving various cause of biliary obstruction. Its major limitation is represented by stent occlusion, followed by life-threatening cholangitis. Microbial colonization of biliary stents was suggested as a cause of stent occlusion through clogging process. ${ }^{28}$ Antimicrobial agent such as broad spectrum antibiotics or bacteriostatic silver ion containing or eluting metallic biliary stent may reduce metallic stent related complications.

\section{BIOABSORBABLE STENT}

Biodegradable polymer stent had been used in urethral stenosis. Kemppainen et al. ${ }^{29}$ placed biodegradable self-reinforced stent made of poly-L-lactide (SR-PLLA) in 16 male rabbits after urethrotomy. In this report, authors concluded biodegradable SR-PLLA is promising material for a urethral stent to prevent re-stenosis of urethral strictures. Biodegradable stent had been used for benign esophageal strictures by Fry and Fleischer ${ }^{30}$ in 1997. Biodegradable stents are known to be absorbed with 8-10 weeks, thus preventing long term tissue reaction and stenosis. But, hyperplastic tissue reaction occurs in conjunction with biodegradable polymer stent degradation and the severity of the tissue response and the time to complete stent degradation, both important factors when considering pateitns for placement of a biodegradable stent. A severe biodegradable stent stenosis can be occurred due to hyperplastic tissue reaction. ${ }^{31}$ SX ELLA-BD stent (Ella-CS) which is woven in a standard construction from a monofilament of polydioxanone is currently available in European countries. ${ }^{32}$ Biodegradable polymers can be used for drug release represent the next technological modification and preliminary results are favorable in vascular system and clinical efficacy as first-generation drug eluting stent, but gastrointestinal application has not been reported yet. ${ }^{33}$

\section{REFERENCES}

1. Wallace MJ, Charnsangavej C, Ogawa K, et al. Tracheobronchial tree: expandable metallic stents used in experimental and clinical applications. Work in progress. Radiology 1986;158:309-312.

2. Fujiwara Y, Sawada S, Tanabe Y, Yoshida K, Katsube Y. Experimental evaluation of expandable metallic stent placement in the trachea, esophagus and urethra. Rinsho
Hoshasen 1990;35:557-562.

3. Karnel F, Jantsch H, Niederle B. Implantation of a metal stent in a malignant stenosis in a colon interposition. Rofo 1991;154:120-122.

4. Kozarek RA, Ball TJ, Patterson DJ. Metallic self-expanding stent application in the upper gastrointestinal tract: caveats and concerns. Gastrointest Endosc 1992;38:1-6.

5. Neuhaus H, Hoffmann W, Dittler HJ, Niedermeyer HP, Classen M. Implantation of self-expanding esophageal metal stents for palliation of malignant dysphagia. Endoscopy 1992;24:405-410.

6. Song HY, Choi KC, Kwon HC, Yang DH, Cho BH, Lee ST. Esophageal strictures: treatment with a new design of modified Gianturco stent. Work in progress. Radiology 1992;184:729-734.

7. Grundy A. The Strecker Esophageal stent in the management of oesophageal strictures: technique of insertion and early clinical experience. Clin Radiol 1994;49:421-424.

8. Song HY, Park SI, Jung HY, et al. Benign and malignant esophageal strictures: treatment with a polyurethane-covered retrievable expandable metallic stent. Radiology 1997; 203:747-752.

9. Krokidis M, Fanelli F, Orgera G, Bezzi M, Passariello R, Hatzidakis A. Percutaneous treatment of malignant jaundice due to extrahepatic cholangiocarcinoma: covered Viabil stent versus uncovered Wallstents. Cardiovasc Intervent Radiol 2010;33:97-106.

10. Castano R, Lopes TL, Alvarez O, Calvo V, Luz LP, Artifon EL. Nitinol biliary stent versus surgery for palliation of distal malignant biliary obstruction. Surg Endosc. Forthcoming 2010. DOI: 10.1007/s00464-010-0903-7.

11. Maetani I, Nambu T, Omuta S, Ukita T, Shigoka $H$. Treating bilio-duodenal obstruction: combining new endoscopic technique with $6 \mathrm{Fr}$ stent introducer. World J Gastroenterol 2010;16:2828-2831.

12. Isayama H, Kawabe T, Nakai Y, et al. Management of distal malignant biliary obstruction with the ComVi stent, a new covered metallic stent. Surg Endosc 2010;24:131-137.

13. Krokidis ME, Hatzidakis AA. Percutaneous transcholecystic placement of an ePTFE/FEP-covered stent in the common bile duct. Cardiovasc Intervent Radiol 2010;33:639-642.

14. Lee JH, Kang DH, Kim JY, et al. Endoscopic bilateral metal stent placement for advanced hilar cholangiocarcinoma: a pilot study of a newly designed Y stent. Gastrointest Endosc 2007;66:364-369.

15. van Boeckel PG, Repici A, Vleggaar FP, et al. A new metal stent with a controlled-release system for palliation of malignant dysphagia: a prospective, multicenter study. Gastrointest Endosc 2010;71:455-460.

16. Schembre D. Advances in esophageal stenting: the evolution of fully covered stents for malignant and benign disease. Adv Ther 2010;27:413-425.

17. Conio M, Blanchi S, Filiberti R, De Ceglie A. Self-expanding plastic stent to palliate symptomatic tissue in/overgrowth after self-expanding metal stent placement for esophageal cancer. Dis Esophagus. Forthcoming 2010.

18. Uitdehaag MJ, Siersema PD, Spaander MC, et al. A new fully covered stent with antimigration properties for the palliation of malignant dysphagia: a prospective cohort study. Gastrointest Endosc 2010;71:600-605.

19. Uno Y, Obara K, Kanazawa K, Sasaki Y, Fukuda S, 
Munakata A. Stent implantation for malignant pyloric stenosis. Gastrointest Endosc 1997;46:552-555.

20. Januschowski R. Stents for the palliative treatment of malignant gastric outlet stenoses. Dtsch Med Wochenschr 1997;122:578-582.

21. Jung GS, Song HY, Kang SG, et al. Malignant gastroduodenal obstructions: treatment by means of a covered expandable metallic stent-initial experience. Radiology 2000;216:758-763.

22. Kim GH, Kang DH, Lee DH, et al. Which types of stent, uncovered or covered, should be used in gastric outlet obstructions? Scand J Gastroenterol 2004;39:1010-1014.

23. Tejero E, Mainar A, Fernandez L, Tobio R, De Gregorio MA. New procedure for the treatment of colorectal neoplastic obstructions. Dis Colon Rectum 1994;37:11581159.

24. Choo IW, Do YS, Suh SW, et al. Malignant colorectal obstruction: treatment with a flexible covered stent. Radiology 1998;206:415-421.

25. Guo SR, Wang ZM, Zhang YQ, et al. In vivo evaluation of 5 -fluorouracil-containing self-expandable nitinol stent in rabbits: efficiency in long-term local drug delivery. J Pharm Sci 2010;99:3009-3018.

26. Lee DK, Kim HS, Kim KS, et al. The effect on porcine bile duct of a metallic stent covered with a paclitaxel-in- corporated membrane. Gastrointest Endosc 2005;61:296301.

27. Lee SS, Shin JH, Han JM, et al. Histologic influence of paclitaxel-eluting covered metallic stents in a canine biliary model. Gastrointest Endosc 2009;69:1140-1147.

28. Guaglianone E, Cardines R, Vuotto C, et al. Microbial biofilms associated with biliary stent clogging. FEMS Immunol Med Microbiol 2010;59:410-420.

29. Kemppainen E, Talja M, Riihela M, Pohjonen T, Tormala P, Alfthan O. A bioresorbable urethral stent. An experimental study. Urol Res 1993;21:235-238.

30. Fry SW, Fleischer DE. Management of a refractory benign esophageal stricture with a new biodegradable stent. Gastrointest Endosc 1997;45:179-182.

31. Hair CS, Devonshire DA. Severe hyperplastic tissue stenosis of a novel biodegradable esophageal stent and subsequent successful management with high-pressure balloon dilation. Endoscopy 2010;42 Suppl 2:E132-E133.

32. Stivaros SM, Williams LR, Senger C, Wilbraham L, Laasch HU. Woven polydioxanone biodegradable stents: a new treatment option for benign and malignant oesophageal strictures. Eur Radiol 2010;20:1069-1072.

33. Raber L, Windecker S. Current status of drug-eluting stents. Cardiovasc Ther. Forthcoming 2010. 